\title{
Study of the Academic Stress In Relation To Personality, Intelligence, and Achievement Motivation among Secondary School Students With Reference To Their Gender
}

\author{
Dr. Amit Kumar Gosar, Stacy Wilson, Saindhavi Venkatraman
}

\begin{abstract}
The study has been carried out with the purpose of understanding the relationship of academic stress in the school children with various other variables like their intelligence, their personality in terms of extraversion and introversion and their achievement motivation. The study was carried out on the students of higher secondary schools from Navi Mumbai and 120 students with equal numbers of male and female students were recruited for this study. Data for this study was collected using various validated instruments such as Cattell's Culture Fair Intelligence Test, TJEPQR-S, Bisht Battery of Stress Scales and Deo-Mohan Achievement Motivation Scale. Various statistical techniques like correlation coefficient and t test were employed for analyzing the data.

The correlation coefficients between Academic stress and other variables like Intelligence, personality and achievement motivation were found to be $-\mathbf{0 . 7 7 ,}-\mathbf{- 0 . 8 7}$ and $\mathbf{- 0 . 6 6}$ respectively, which are showing high negative correlation. This indicates that academic stress is high with students having low IQ and also with students who are introverts. Similarly students with high academic stress have low achievement motivation.

The comparison of means using $t$ test reveals that there is no significant difference in the stress levels of male and female students. However, there is significant difference in stress levels of extrovert and introvert students and students with low and high IQ. It is also observed that there is a significant difference in the level of achievement motivation in students with low academic stress and high academic stress.
\end{abstract}

Index Terms-Academic stress, Intelligence, Personality, Extraversion, Introversion, Achievement motivation.

\section{INTRODUCTION}

Everyone in their lifetime gets exposed to stress at some or other point of time. Distress is an uncomfortable situation that generally affects quality of the life and the sense of wellbeing. When the environmental factors provides stimuli which disturbs the state of homeostasis of an individual, the available resources will decide the level of stress. Academic environments can be highly competitive, and students must rely on their coping abilities to handle school-related stress successfully. High school students experience stress in many situations. School education is one of the most important phase of an individual's life. The academic performance at this is very crucial in deciding the next career stage in terms

Dr. Amitkumar Gosar, School of Psychology, California Center University, 1301, Clay St; Oakland, California, USA,

Stacy Wilson, School of Psychology, California Center University, 1301, Clay St; Oakland, California, USA

Saindhavi Venkatraman, Academic Counsellor; IGNOU, India. of academic stream in their life. Higher levels of academic stress at this stage can result in adverse effects that are significant and chronic. An excess of academic stress can lead to increased frequency of physical and psychological problems like anxiety, nervousness, depression and other stress related disorders, which in turn can affect their academic performance.

The extent to feel such a stress can also vary from individual to individual. When students' aspirations are too high to reach but his abilities, interests, attitudes and capacities do not match with it, one may feel stress. An individual may excel in limited areas but sometimes when one wants to excel in every walk of life without considering one's own capabilities or under estimating own self may suffer from stress. Worldwide, Anxiety disorder has been seen in $8 \%$ of the adolescents and children. Academic stress is also positively correlated with the parenteral pressure.

The cases of suicide has also been reportedly increased in the high school students. The data says that the percentage of high school students who reported that they had thought seriously about committing suicide is up by $25 \%$ from 2009 to 2017. Female high school students reported seriously considering suicide at nearly twice the rate of their male counterparts in 2017 (22.1 and 11.9 percent, respectively).

Students learn more and more to achieve excellence. But when they don't meet their targets, they chose wrong methods of study like rote memorization etc. which lead them towards stress. The psychologists and educationists have been focusing their research proposals in the area of stress. They remained mostly in the fields of occupational stress, stressful life events and stress due to some chronic diseases etc. But less attention has been paid to the issue of academic stress realizing the present day need in the area of education where focus is upon mobilizing and directing the inner potentialities of students to cope with difficulties and achieve better. The variable of academic stress has been selected for investigation especially as it exists in relation to one's cognitive functioning. The other variables selected for the present study are personality, intelligence and achievement motivation. It is yet to be explored whether more intelligent students take the academic requirements as challenge and utilize their maximum energy to do the best. Personality has different traits and any particular trait may help the individuals to react in a specific way for coming possibilities. Some students want to achieve the standard of excellence in every sphere of life but academic stress plays its role everywhere. It may vary with varying levels of personality, intelligence and achievement motivation. Hence, 
the investigator took the present study to account for the issues of academic stress.

\section{TOOLS USED}

To achieve the objectives of the study following tools were used:

A. Cattell's Culture Fair Intelligence Test.

B. The short-form of the revised Junior Eysenck Personality questionnaire (JEPQR-S)

C. Bisht Battery of Stress Scales made by Abha Rani Bisht.

D. Deo-Mohan Achievement Motivation Scale by Deo-Mohan.

\section{RESULTS AND DISCUSSION}

Out of 150 students selected for this study, after administration of all the questionnaires, data of 120 students was selected in equal ratio of male and female students based on their lie scores came within the limit. All the raw scores obtained from all the instruments used are attached as appendix 5.

\section{A. Academic stress}

$\mathrm{H} 0 \mathrm{~A}$ : There is no significant difference in the Academic stress of male and female Secondary school students.

To study the level of Academic stress among school children the data were analyzed. To find out academic stress among school children the scores obtained on academic stress scale were computed. Mean score and its standard deviation have been shown in Table 1

Table 1: Academic stress Among School Children

\begin{tabular}{ccccc}
\hline $\begin{array}{c}\text { Academic } \\
\text { Stress }\end{array}$ & N & Mean & Std.Dev & Variance \\
\hline Male & 60 & $\mathbf{6 6 . 8 8}$ & $\mathbf{1 1 . 4 9}$ & $\mathbf{1 3 1 . 9 7}$ \\
Female & 60 & $\mathbf{6 3 . 2 6}$ & $\mathbf{1 2 . 4 0}$ & $\mathbf{1 5 3 . 8 0}$ \\
\hline
\end{tabular}

The children are further categorized w.r.t. their scores of Academic stress into Students with Low stress, Moderate stress and high stress and the data is tabulated in the Table 2.

Table 2 : Categorization of the students with different stress level

\begin{tabular}{ccccc}
\hline & $\begin{array}{c}\text { Low } \\
\text { Stress }\end{array}$ & $\begin{array}{c}\text { Moderate } \\
\text { Stress }\end{array}$ & $\begin{array}{c}\text { High } \\
\text { Stress }\end{array}$ & Total \\
\hline Overall & 65 & 55 & 17 & 120 \\
$\%$ & 54.17 & 45.83 & 14.17 & 100.00 \\
\hline Male & 28.00 & 32.00 & 9.00 & 60 \\
$\%$ & 46.67 & 53.33 & 15.00 & 100.00 \\
\hline Female & 37.00 & 23.00 & 8.00 & 60 \\
$\%$ & 61.67 & 38.33 & 13.33 & 100.00 \\
\hline
\end{tabular}

From the above data it is seen that $54.17 \%$ students fall in low stress category, about $45.83 \%$ students fall under Moderate stress category and about $14.17 \%$ of the students fall under high stress category. However, more number of female students falls under low stress category $(61.67 \%)$ as compare to male students $(46.67 \%)$ but more number of male students fall under moderate stress category $(53.33 \%)$ as compare to female students $(38.33 \%)$. The high stress percentage are similar for both male and female students, which are $15.0 \%$ and $13.33 \%$ respectively.

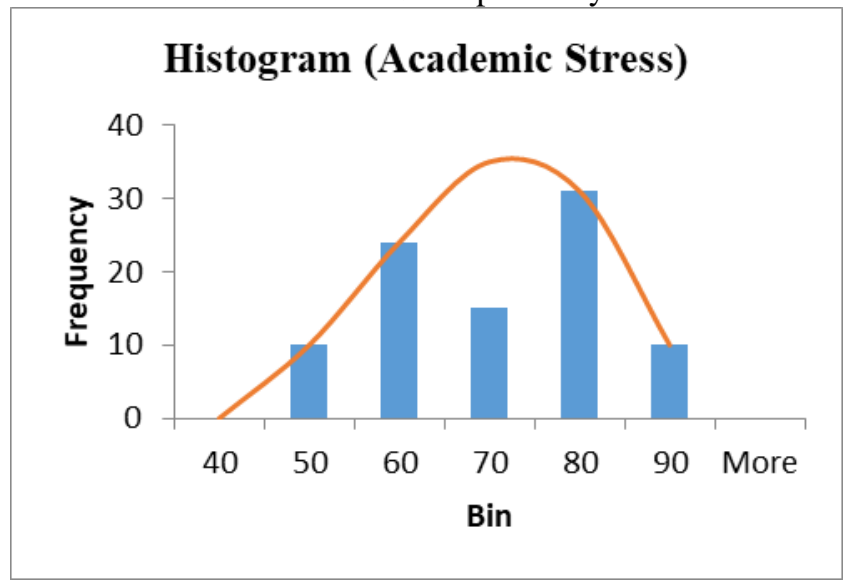

Figure 1 : Distribution of Academic stress amongst school students

The Histogram of the distribution of the academic stress has been plotted in figure 1 . And the distribution has been found to be near to normal.

Academic stress among school children in relation to their gender

Hypothesis testing of $\mathbf{H}_{0 \mathrm{~A}}$

$\mathbf{H}_{\mathbf{0 A}}$ : There is no significant difference in the Academic stress of male and female Secondary school students.

For testing of the hypothesis $\mathrm{H}_{0 \mathrm{~A}}$, the scores of academic stress of 60 male students and 60 female students were taken and the statistical analysis was done using t-test. $t$ cal value obtained by this analysis at the significance level of 0.05 is reported in the table no.3.

Table 3 : $t$ - test results of academic stress of male and female students.

\begin{tabular}{lcc}
\hline & $\begin{array}{c}\text { (Male } \\
\text { students) }\end{array}$ & $\begin{array}{c}\text { (Female } \\
\text { Students })\end{array}$ \\
\hline Mean & 66.88333333 & 63.61666667 \\
Variance & 131.969209 & 153.7997175
\end{tabular}

Observations

60

60

Pearson Correlation

Hypothesized Mean

Difference

0.105206294

df

0

59

t Stat

$\mathbf{1 . 5 8 2 1 1 0 7 8 3}$

$\mathrm{P}(\mathrm{T}<=\mathrm{t})$ one-tail

0.059485347

t Critical one-tail

$\mathbf{1 . 6 7 1 0 9 3 0 3 2}$

$\mathrm{P}(\mathrm{T}<=\mathrm{t})$ two-tail

0.118970694

t Critical two-tail

2.000995378

The $t$ cal value of 1.58 is less than that of $t$ critical value of 1.67 at 0.05 level of significance. Hence the null hypothesis is accepted. This means that there is no significant difference in the stress level of Male and Female students. Intelligence 
$\mathbf{H}_{\mathbf{0 B}}$ : There is no statistically significant relationship between Academic stress of Secondary school students and their level of intelligence.

$\mathbf{H}_{\mathbf{0 C}}$ : No significant difference will exist in the Academic stress of Secondary school students having high and low intelligence.

Academic stress among school children having different levels of intelligence

The objective of the study was to find the impact of intelligence on the academic stress among school children having different levels of intelligence. The data obtained in this study w.r.t. IQ scores are presented below. The mean, standard deviation and variance of the data is presented in the table No. 4.

Table 4 : IQ scores of schools childrens.

\begin{tabular}{lllll} 
IQ scores & $\mathrm{N}$ & Mean & Std.Dev & Variance \\
\hline Male & 60 & $\mathbf{1 2 6 . 7 0}$ & $\mathbf{8 . 1 6}$ & $\mathbf{6 6 . 5 2}$ \\
Female & 60 & $\mathbf{1 2 9 . 4 5}$ & $\mathbf{8 . 0 5}$ & $\mathbf{6 4 . 9 7}$ \\
\hline
\end{tabular}

From the IQ scores of 120 students (60 male and 60 female), the students are further categoriesed into three categoty of IQ viz. a. Students with Average IQ (IQ scores below 120), b. Students with Superior IQ (IQ scores between 120 and 140) and Veru superior IQ (IQ scores above 140). The academic stress of these sub group was checked and the average academic stress for each group was calculated and the data is reported in the table no. 5. From the data it is found that the average academic stress scores of students with Average IQ (average academic stress scores of 75.3) is much higher than the students with superior IQ (average academic stress scores of 63.58), which is further higher than that of very superior IQ (average academic stress scores of 55.0).

Table 5 : Categorization of the students with different IQ levels and their academic stress scores

$\begin{array}{lll}\begin{array}{l}\text { Average IQ } \\ \text { (Below }\end{array} & \begin{array}{l}\text { Superior IQ } \\ \text { (Between }\end{array} & \begin{array}{l}\text { Very superior } \\ \text { IQ }\end{array} \\ 120) & 120 \text { to } 140) & \text { (Above 140) }\end{array}$

\begin{tabular}{llll}
\hline $\begin{array}{l}\text { Number of } \\
\text { Students }\end{array}$ & 20 & 96 & 4 \\
\hline
\end{tabular}

\begin{tabular}{llll}
\hline $\begin{array}{l}\text { Academic } \\
\text { stress score }\end{array}$ & $50-85$ & $60-85$ & $54-62$ \\
range & & & \\
\hline $\begin{array}{l}\text { Average } \\
\text { academic }\end{array}$ & 75.3 & 63.58 & 55 \\
$\begin{array}{l}\text { stress } \\
\text { scores }\end{array}$ & & & \\
\hline
\end{tabular}

scores

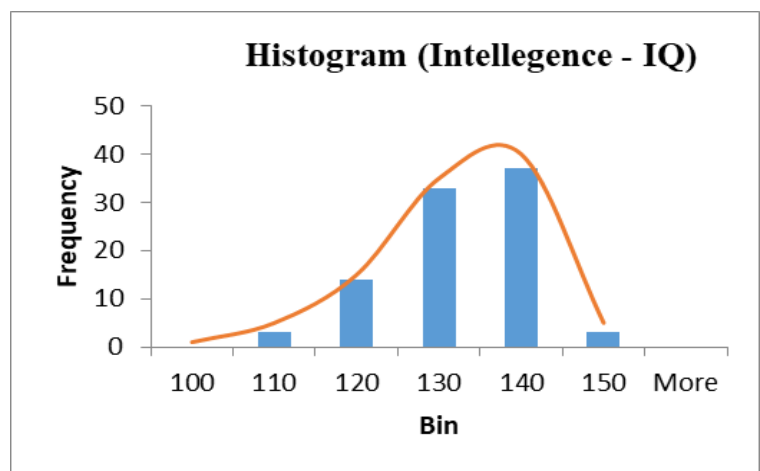

Figure 2 : Distribution of IQ scores of school students

The Histogram of the distribution of the IQ scores of the school students has been plotted in figure 2. And the distribution has been found to be near to normal.

\section{Hypothesis testing of $\mathrm{H}_{\mathbf{0 B}}$}

$\mathbf{H}_{\mathbf{0 B}}$ : There is no statistically significant relationship between Academic stress of Secondary school students and their level of intelligence.

For testing of the hypothesis $\mathrm{H}_{0 \mathrm{~B}}$, the correlational analysis of Academic stress scores vs. IQ scores of the students was carried out. The obtained correlation is plotted in the figure 3.

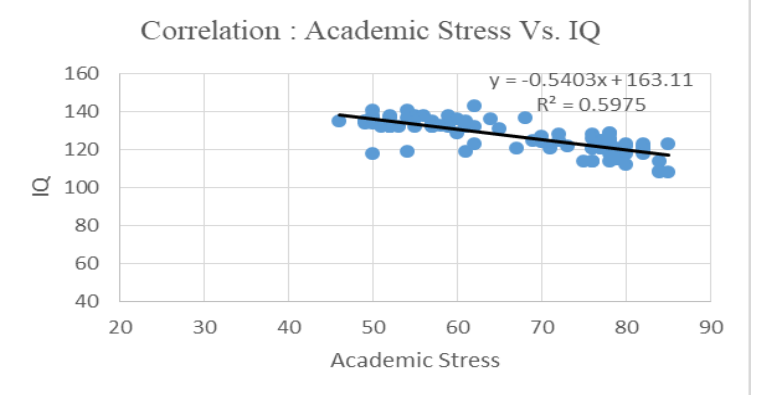

Figure 3 : Correlation between academic stress and IQ scores of the students

The correlation coefficient obtained for this study was -0.77 . This means that the obtained correlation is high and negative. Hence, null hypothesis is rejected and alternate hypothesis is accepted, which means that there is a significant relationship between intellegence and academic stress of the students and the relation is high and negative. This indicates that the academic stress increases as the IQ scores decreases and academic stress decreases as IQ scores increases. This correlation was found to be higher in male students $(-0.81)$ as compare to female students (-0.73).

Hypothesis testing of $\mathbf{H}_{0 \mathrm{C}}$

$\mathbf{H}_{\mathbf{0 C}}$ : No significant difference will exist in the Academic stress of Secondary school students having high and low intelligence.

For testing of hypotheis $\mathrm{H}_{0 \mathrm{C}}$, students were divided into two groups based on their IQ scores. The students with IQ scores up to 125 are considered low IQ scores and students having IQ more than 125 are considered high IQ scores. Then academic scores of students of these two groups were compared with the help of $\mathrm{t}$ test. The obtained results are tabulated in tahble no. 6 .

Table 6 : $t$ - test results of academic stress of low IQ and high IQ students.

\begin{tabular}{llll}
\hline & $\begin{array}{l}\text { Low } \\
\text { Group }\end{array}$ & $\begin{array}{l}\text { High } \\
\text { Group }\end{array}$ & IQ \\
\hline Mean & 75.936 & 58.370 &
\end{tabular}



School Students With Reference To Their Gender

\begin{tabular}{lll} 
Variance & 66.235 & 73.764 \\
Observations & 47.000 & 73.000 \\
Pooled Variance & 70.829 & \\
Hypothesized & Mean & \\
Difference & 0.000 & \\
df & 118.000 \\
t Stat & $\mathbf{1 1 . 1 6 1}$ \\
P(T<=t) one-tail & 0.000 \\
t Critical one-tail & $\mathbf{1 . 6 5 8}$ \\
P(T<=t) two-tail & 0.000 \\
t Critical two-tail & 1.980 \\
\hline
\end{tabular}

The $t$ cal value of 11.16 is higher than that of $t$ critical value of 1.658 at 0.05 level of significance. Hence the null hypothesis is rejected and alternate hypothesis is accepted. This means that there is a significant difference in the stress level of low IQ and high IQ students. This is also evident from the hypothesis testing of hypothesis $\mathrm{H}_{\mathrm{OB}}$ that there is a negative and high correlation between IQ scores and Academic stress of the students. Hence students with high IQ scores will have low academic stress and students with low IQ scores will have high levels of academic stress.

\section{Personality}

$\mathbf{H}_{0 \mathrm{D}}$ : There is no statistically significant relationship between Academic stress of extroverts and introverts.

$\mathbf{H}_{\mathbf{0 E}}$ : There is no significant difference in the Academic stress of extroverts and introverts.

Academic stress among school children having different levels of personality

The objective of the study was to find the impact of personality in terms of extraversion and introversion on the academic stress among school children. The data obtained in this study are presented below. The mean, standard deviation and variance of the data is presented in the table No. 7 .

Table 7 : Personality scores interms of extraversion and introversion of school children.

\begin{tabular}{lcccc}
\hline Personality & N & Mean & Std.Dev & Variance \\
\hline Male & 60 & $\mathbf{6 . 1 0}$ & $\mathbf{2 . 1 8}$ & $\mathbf{4 . 7 4}$ \\
Female & 60 & $\mathbf{6 . 6 7}$ & $\mathbf{2 . 5 4}$ & $\mathbf{6 . 4 3}$ \\
\hline
\end{tabular}

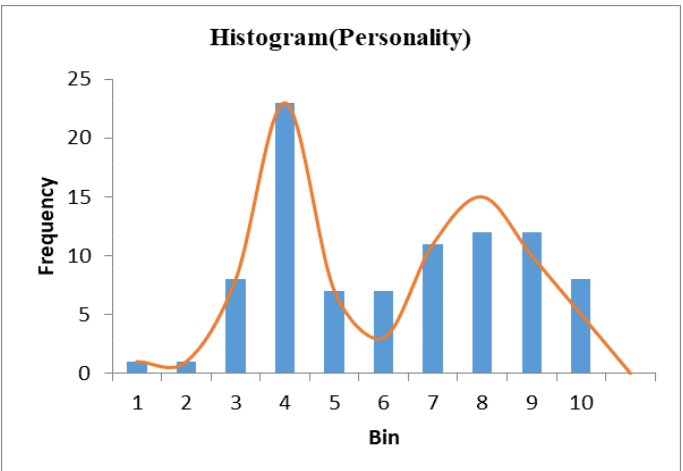

Figure 4 : Distribution of Personality scores of school students
The Histogram of the distribution of the personality scores of the school students has been plotted in figure 4 . The obtained distribution is normal and bimodal. This indicates that there exists two distinct group of introvert and extrovert students and both have normal distribution of their scores.

Hypothesis testing of $\mathbf{H}_{\mathbf{0 D}}$

$\mathbf{H}_{\mathbf{0 D}}$ : There is no statistically significant relationship between Academic stress of extroverts and introverts.

For testing of the hypothesis $\mathrm{H}_{0 \mathrm{D}}$, the correlational analysis of Academic stress scores vs. Personality scores of the students was carried out. The obtained correlation is plotted in the figure 5 .

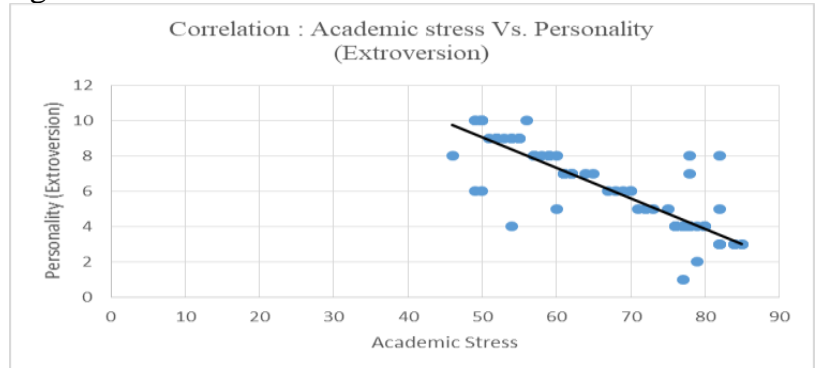

Figure 5 : Correlation between academic stress and Personality scores of the students

The correlation coefficient obtained for this study was -0.87 . This means that the obtained correlation is high and negative. Hence, null hypothesis is rejected and alternate hypothesis is accepted, which means that there is a significant relationship between personality interms of extraversion and introversion and academic stress of the students and the relation is high and negative. This indicates that the academic stress is high in case of students with low scores of personality, thatis introverts and Academic stress is low in case students with high personality scores, that is extroverts. This correlation was found to be similar in both male students $(-0.87)$ and female students $(-0.85)$.

Hypothesis testing of $\mathrm{H}_{\mathbf{0 E}}$

$\mathbf{H}_{\mathbf{0 E}}$ : There is no significant difference in the Academic stress of extroverts and introverts.

For testing of hypotheis $\mathrm{H}_{0 \mathrm{E}}$, students were divided into two groups based on their Personality scores. The students with personality scores more than 5 were considered Extroverts and students with personality scores from 0 to 5 are considered as introverts. Then academic scores of students of these two groups were compared with the help of $t$ test. The obtained results are tabulated in tahble no. 8 .

Table 8 : $t$ - test results of academic stress of Extrovert and Introvert students.

\begin{tabular}{lll}
\hline & Introverts & Extroverts \\
\hline Mean & 77.125 & 57.333 \\
Variance & 41.941 & 55.324 \\
Observations & 48.000 & 72.000 \\
Pooled Variance & 49.994 & \\
Hypothesized Mean Difference & 0.000 & \\
df & 118.000 & \\
t Stat & $\mathbf{1 5 . 0 2 2}$ & \\
$\mathrm{P}(\mathrm{T}<=\mathrm{t})$ one-tail & 0.000 &
\end{tabular}




\begin{tabular}{ll} 
t Critical one-tail & $\mathbf{1 . 6 5 8}$ \\
$\mathrm{P}(\mathrm{T}<=\mathrm{t})$ two-tail & 0.000 \\
$\mathrm{t}$ Critical two-tail & 1.980 \\
\hline
\end{tabular}

The $t$ cal value of 15.02 is higher than that of $t$ critical value of 1.658 at 0.05 level of significance. Hence the null hypothesis is rejected and alternate hypothesis is accepted. This means that there is a significant difference in the stress level of Extrovert and Introvert students. This is also evident from the hypothesis testing of hypothesis $\mathrm{H}_{\mathrm{OD}}$ that there is a negative and high correlation between Personality scores and Academic stress of the students. Hence Extrovert students will have low academic stress and introvert students will have high levels of academic stress.

\section{Achievement Motivation}

$\mathbf{H}_{\mathbf{0 F}}$ : There is no statistically significant relationship between Academic stress of Secondary school students and their level of achievement motivation.

$\mathbf{H}_{\mathbf{0 G}}$ : No significant difference will exist in the Academic stress of Secondary school students having high and low level of achievement motivation.

Academic stress among school children having different levels of achievement motivation

The objective of the study was to find the impact of the academic stress on the achievement motivation of the school children. The data obtained in this study are presented below. The mean, standard deviation and variance of the data is presented in the table No. 9.

Table 9 : Acievement Motivation scores of school children.

\begin{tabular}{lllll}
\hline $\begin{array}{l}\text { Achievement } \\
\text { Motivation }\end{array}$ & N & Mean & StDev & Variance \\
\hline Male & 60 & $\mathbf{1 4 8 . 4 5}$ & $\mathbf{2 7 . 4 9}$ & $\mathbf{7 5 5 . 6 8}$ \\
Female & 60 & $\mathbf{1 5 3 . 3 8}$ & $\mathbf{2 8 . 5 4}$ & $\mathbf{8 1 4 . 8 2}$ \\
\hline
\end{tabular}

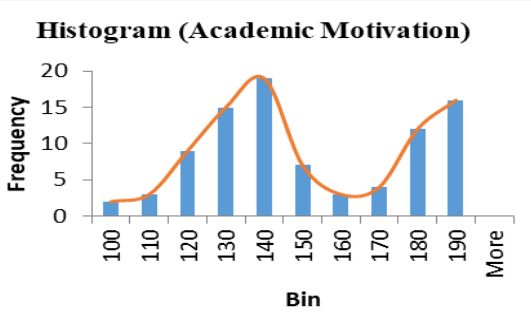

Figure 6 : Distribution of Achievement motivation scores of school students

The Histogram of the distribution of the Achievement motivation scores of the school students has been plotted in figure 6 . The obtained distribution is normal and bimodal. Hypothesis testing of $\mathrm{H}_{0 \mathrm{~F}}$

$\mathbf{H}_{0 \mathrm{~F}}$ : There is no statistically significant relationship between Academic stress of Secondary school students and their level of achievement motivation.

For testing of the hypothesis $\mathrm{H}_{0 \mathrm{~F}}$, the correlational analysis of Academic stress scores vs. Achievement motivation scores of the students was carried out. The obtained correlation is plotted in the figure 7.

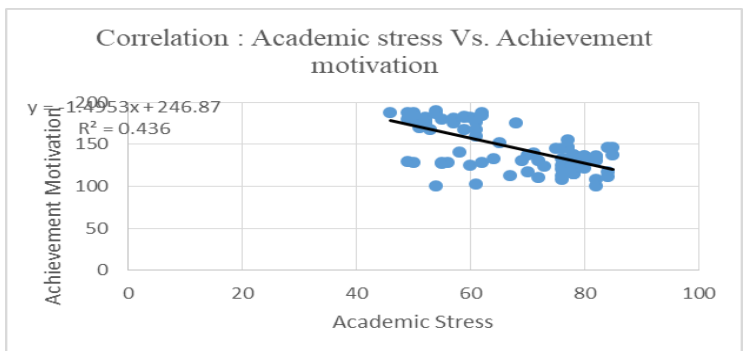

Figure 7 : Correlation between academic stress and Achievement motivation scores of the students

The correlation coefficient obtained for this study was -0.66 . This means that the obtained correlation is moderate and negative. Hence, null hypothesis is rejected and alternate hypothesis is accepted, which means that there is a significant relationship between academic stress and achievement motivation of the students and the relation is moderate and negative. This indicates that when the academic stress is high the students will have low achievement motivation and when the academic stress is low students will have high achievement motivation. This correlation was found more in case of male students (-0.72) as compare to female students $(-0.62)$.

Hypothesis testing of $\mathbf{H}_{\mathbf{0 G}}$

$\mathbf{H}_{\mathbf{0 G}}$ : No significant difference will exist in the Academic stress of Secondary school students having high and low level of achievement motivation.

For testing of hypotheis $\mathrm{H}_{\mathrm{OG}}$, students were divided into two groups based on their Achievement motivation scores. The students with Achievement motivation scores up to 145 were considered low in achievement motivation and students with Achievement motivation scores more than 145 are considered high in achievement motivation. Then academic scores of students of these two groups were compared with the help of $t$ test. The obtained results are tabulated in tahble no. 10.

Table 10 : $t$ - test results of academic stress of students with low and high achievement motivation.

\begin{tabular}{lll}
\hline & $\begin{array}{l}\text { Low Ach. } \\
\text { Mot. }\end{array}$ & $\begin{array}{l}\text { High Ach. } \\
\text { Mot. }\end{array}$ \\
\hline Mean & 73.322 & 57.443 \\
Variance & 91.084 & 72.251 \\
Observations & 59.000 & 61.000 \\
df & 118.000 & \\
t Stat & $\mathbf{9 . 6 3 2}$ & \\
P(T<=t) one-tail & 0.000 & \\
t Critical one-tail & $\mathbf{1 . 6 5 8}$ & \\
P(T<=t) two-tail & 0.000 & \\
t Critical two-tail & 1.980 & \\
\hline
\end{tabular}

The $t$ cal value of 9.63 is higher than that of $t$ critical value of 1.658 at 0.05 level of significance. Hence the null hypothesis is rejected and alternate hypothesis is accepted. This means that there is a significant difference in the Achievement motivation of students with low and high level of academic stress. This is also evident from the hypothesis testing of hypothesis $\mathrm{H}_{\mathrm{OF}}$ that there is a negative and moderate correlation between Achievement motivation scores and Academic stress of the students. Hence students 
with high academic stress will have low achievement motivation and students with low academic stress will have high achievement motivation.

\section{CONCLUSION}

Based on the current research study and its result, it is concluded that both male and female students have similar levels of academic stress, intelligence, personality distribution and achievement motivation. From the results it is also concluded that academic stress has a strong relationship with variables like intelligence, personality in terms of extraversion and introversion and achievement motivation. The relationship of academic stress with all these variables was found negative. The small size of the research sample made it disadvantageous in generalizing the results of the study.

Owing to the present study following conclusions were drawn:-

- Majority of the school children feel academic stress.

- Male and female school children feel similar levels of academic stress.

- The school children having high intelligence feel less stress than those with low intelligence.

- Introverts suffer more academic stress than extroverts.

- The school children having high academic stress feels less achievement motivation than those who have low level of stress.

\section{ACKNOWLEDGMENT}

I feel indebted to my guide Dr. Stacy Wilson and Co- Guide Ms. Saindhavi Venkatraman for the completion of the dissertation entitled "to study the academic stress in relation to personality, intelligence, and achievement motivation among secondary school students with reference to their gender" The present work could be completed only because of the able guidance and affectionate attitude of my guide Dr. Stacy Wilson and CoGuide Ms. Saindhavi Venkatraman I am thankful to all respondents and all those who assisted me by supplying the requisite information towards the completion of the questionnaire there by enable me to collect the relevant data.
Praachi Journal of Psycho-Cultural Dimensions, 15, (12), pp. 111-114.

[8] Block, J., Weiss, D.S. and Thorne, A (1979) "How Relevant is a Semantic Similarity Interpretation of Personality Rating?" Journal of Personality and Social Psychology. 37, (10), pp. 55-74.

[9] Borich, G.D. and Tombari, M.L. (1997) ", New York: Addison Wesley Publishers Inc.

[10] Braden, J. P. (1995). "Intelligence and personality in school and educational psychology." International handbook of personality and intelligence, pp. 621-650 New York: Plenum.

[11] Brown, D. (2000). "Principles of language learning and teaching". White Plains, NY: Longman.

[12] Carskadon, T. (1978). "Use of the Myers-Briggs Type Indicator in psychology courses and discussion groups". Teaching of Psychology, 5(3), pp. 140-142.

[13] Choudhary, Nirmala (1971) "The Relationship Between Achievement and Anxiety, Intelligence, Sex, Social Class and Vocational Aspirations." Unpublished Doctoral Thesis, Chandigarh: Department of Psychology, Panjab University.

[14] Choudhary, Uma (1974) "Thematic Apperception Test, Indian Adaptation of Murray, H.A. (1943) Thematic Apperception Test", U.S.A.: Harvard College.

[15] Clark, M.H. and Schroth, C.A. (2010) "Examining Relationships Between Academic Motivation and Personality Among College Students. Learning and Individual Differences”, 20, 1, pp. 19-24, February.

[16] Cullain (2000) "The Effects of Social Stories on Anxiety Levels and Excessive Behavioral Expressions of Elementary School-aged Children with Autism.” Dissertation Abstracts International, 62, (7), 2002.

[17] Das, I and Rai, S. (2004) "Impact of Religious Beliefs Leisure Time Activities on Stress of Elderly". Psycho-Lingua, 34(2), pp. 132-134.

[18] Dash, W.N., Kantha, S.K. and Dash, M. (1999) "Cognitive Patterns of Good and Poor Readers Varying in Intelligence". Indian Psychological Review, 52, 53 (3-4), pp. 109-122.

[19] Denscombe, M. (2000) "Social Conditions for Stress". British Educational Research Journal, 26, 3, pp. 259-265.

[20] Dimitrov.G (2017). "A study on the impact of Academic Stress among college students in India", Ideal Research. 2(4).

[21] Prabu Suresh P (2015). "A study on academic stress among higher secondary stress," International Journal of Humanities and Social Science Invention, 4(10), pp. 63-68.

[22] Reddy,K.J., Menon. K., Anjanathattil (2018). "Academic Stress and its Sources among University Students", Biomed Pharmacol Journal,11(1), pp. 531-537.

[23] Subramani, C. and Kadhiravan, S. (2017). "Academic Stress and Mental Health among High School Students", Indian Journal of Applied Research, 7(5).

[24] Sharma,B. Kumar,A. and Sarin,J. (2016). "Academic Stress, Anxiety, Remedial Measures dopted and Its Satisfaction among Medical Student", A Systematic Review, International Journal of Health Sciences and Research, 6(7), pp. 368-376

\section{REFERENCES}

[1] Acharya, Y.T. (1996) "The Relationship Between Personality and Essential Hypertension”. Indian Psychological Review, 46, 3-4, pp. 50-56.

[2] Agarwal, A and Khokhar, C.P. (1999) "Frustration and Anxiety in Diabetics and Normals". Praachi Journal of Psycho-Cultural Dimensions, 15, 2, pp. 157-161.

[3] Agarwal, S.C. and Singh, S. (2004) "Achievement Motivation of Co-Educational and Single Sex Educational Secondary Students". Indian Journal of Psychometry and Education,35,1, pp. 26-31.

[4] Ahmed, Jasmine (1998) "Achievement Motivation Differences Among Adolescent Boys and Girls of Various Birth Position". Indian Psychological Review, 50, 1, pp. 70-75.

[5] Amit, G., \& Saindhavi, V. (2019). "Literature Review on Examination Stress amongst School Going”. World Journal of Research and Review, 9 (3), pp. 19 - 22.

[6] Barrett, L., \& Connot, R. (1986). "Knowing student personality can help school, classroom, activity participation". NASSP Bulletin, February, pp. 39-45.

[7] Bhatia, Sanjay (1999) "Stress Management in the Work Place". 